\title{
Comparing the Performance of Induction Machine Drive with Different Rotor-Impedance Profiles
}

\author{
Mona N Eskander ${ }^{1,}{ }^{*}$, Sanaa I Amer ${ }^{1}$ \\ ${ }^{1}$ Department of Power Electronics and Energy Conversion, Electronics Research Institute, Cairo, Egypt \\ ${ }^{*}$ Corresponding author Ph: +202-33310553; Fax: +202-33369738; Email: eskander@eri.sci.eg \\ DOI: https://doi.org/10.34256/irjmt2125 \\ Received: 07-03-2021, Revised: 11-03-2021, Accepted: 12-03-2021, Published: 12-03-2021
}

Abstract: This paper compares the performance of a wound rotor induction motor drive (WRIM) with two rotor impedance profiles. The first system involves a diode rectifier followed by variable impedance in the rotor circuit. The second system involves a three-phase variable impedance in the rotor circuit. The comparison concerns the magnitude of starting transients of stator and rotor voltages and currents, the transients settling time of the stator and rotor voltages and currents, the stator and rotor consumed active and reactive power, the electrical torque, and the stable range of operation at sub-and super-synchronous speeds. This comparison is helpful for deciding the more efficient drive to be utilized, the drive with lower harmonics in currents and voltages, and the drive allowing wider speed stable operation range. Better results are obtained for the drive with the three-phase variable impedance connected to the rotor circuit.

Keywords: Wound rotor induction motor, Electrical drive, Rotor impedance, Diode rectifier.

\section{Introduction}

Wound rotor induction motor drives outperform the squirrel cage induction motor drives in many aspects. First, its speed can be varied through an external resistance, which allows maintaining the torque at any value, up to the pull out torque, within the entire speed range by varying the added rotor resistance. Second, high starting torque with restricted starting current for accelerating heavy rotating masses is provided by WRIM drive. Also, during starting the rotor is subjected to damage due to excessive heat, which can be shared by the external resistance, hence protecting the rotor circuit. Availability of full-rated torque at starting, high power factor, absence of line current harmonics, and wide range of operational speed, are other advantages of speed control via rotor resistance [1-9]. In fact these benefits overcome the drawbacks of WRIM higher cost and its need for frequent maintenance.

Most previous researches concerning speed control and starting of WRIM concentrated on adding capacitors to the rotor impedance to improve the power factor and dynamic performance [10,11]. Other researches considered adding chopper to the rotor circuit to vary the rotor impedance for better performance [12]. These methods add to the complexity of control and increase the cost of the drive system by adding more components to the rotor circuit.
These drawbacks are avoided in this research paper by proposing simple methods for controlling the speed of a WRIM drive. The performance of the two proposed simple rotor systems are compared to conclude the better drive from the point of view of operating speed range, harmonics, starting transients, and settling time. The rotor circuit of the first proposed system is connected to a diode bridge rectifier with a variable single-phase impedance at its output. The rotor of the second system is connected to a three-phase variable impedance. The two systems are modeled and simulated using MATLAB/Simulink software. The comparison concerned the voltage and currents transients and their settling time, the stable range of operation, the active and reactive power consumed from the grid, the rotor active and reactive power, and the electric torque response. The simulation results proved that the performance of the system with the three phase rotor impedance is better than the performance of the system with the diode bridge. Lower harmonics, short settling time, and lower voltage and current transients are observed in the drive with three phase impedance in the rotor circuit. 


\section{Mathematical Model of WRIM}

The machine dynamical equations in the $d-q$ axis can be written as [13]:

$\frac{d \wedge_{d s}}{d t}=v_{d s}-r_{s} i_{d s}+w \lambda_{q s}$

$\frac{d \wedge_{q s}}{d t}=v_{q s}-r_{s} i_{q s}+w \lambda_{d s}$

$\frac{d \Lambda_{d r}}{d t}=v_{d r}-r_{r} i_{d r}+\left(w-w_{r}\right) \Lambda_{q r}$

$\frac{d \lambda_{q r}}{d t}=v_{q r}-r_{r} i_{q r}-\left(w-w_{r}\right) \lambda_{d r}$

$\frac{d w_{r}}{d t}=\frac{1}{2 H}\left(T_{e}-T_{L}-B_{m} w_{r}\right)$

$\wedge_{d s}=L_{s} i_{d s}+L_{m} i_{d r}$

$\lambda_{q s}=L_{s} i_{q s}+L_{m} i_{q r}$

$\lambda_{d r}=L_{r} i_{d r}+L_{m} i_{d s}$

$\lambda_{q r}=L_{r} i_{q r}+L_{m} i_{q s}$

$T_{e}=\frac{3 P L_{m}}{4 L_{s}}\left(\lambda_{q s} i_{d r}-\lambda_{d s} i_{q r}\right)$

Where $\ldots \wedge, v, i, \omega, T_{e}$ denote flux, voltage, current, angular speed and electromagnetic torque respectively.

Subscripts $d$ and $q$ denote $d$-axis component and $\mathrm{q}$-axis component in arbitrary $\mathrm{d}$-q reference frame, respectively. $r$ and $L$ denote resistance and inductance, respectively

Suffixes $\mathrm{s}, \mathrm{r}$ and $\mathrm{m}$ denote stator, rotor and mutual quantities respectively; $P$ is the number of pole pairs.

\subsection{The Drive System with Three Phase Impedance In The Rotor Circuit}

The per-phase rotor impedance is:

$\mathrm{Z}_{\mathrm{r}}=\mathrm{R}_{\mathrm{r}}+\mathrm{X}_{\mathrm{r}}+\mathrm{Zext}$

Where Zext is the external impedance that can be varied to improve the dynamic performance of the system and to widen the stable speed range of operation.

\subsection{The Drive System with a Rectifier and Single-Phase Impedance}

Figure 1 shows the bridge rectifier with the variable impedance at its output.

Under the balanced conditions, the three-phase sinusoidal voltages at ac side of the rectifier VA, VB and VC can be written as follows:

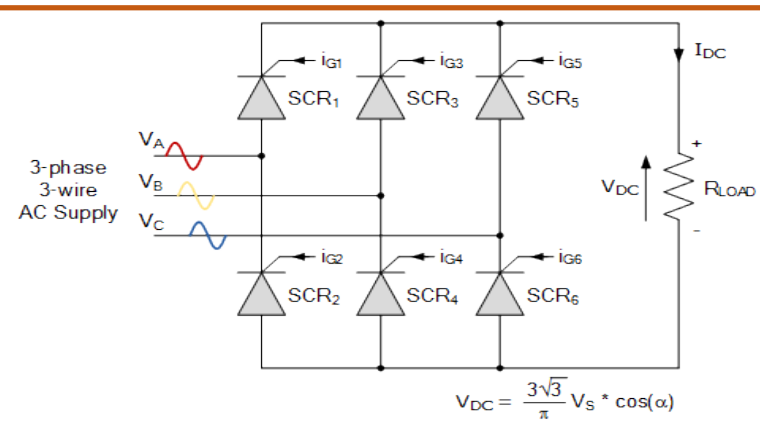

Figure 1 Bridge rectifier with variable impedance.

$$
\mathbf{V}_{a b c}=\left\lfloor\begin{array}{l}
v_{a} \\
v_{b} \\
v_{c}
\end{array}\right\rfloor=V_{m}\left[\begin{array}{c}
\cos (\omega t+\varphi) \\
\cos (\omega t+\varphi-2 \pi / 3) \\
\cos (\omega t+\varphi+2 \pi / 3)
\end{array}\right\rfloor
$$

Where $\mathrm{Va}, \mathrm{V}_{\mathrm{b}}$, and $\mathrm{Vc}$ are the rotor circuit voltages. The DC component of the output voltage is given by:

$$
V_{\text {OUT }}=\frac{3 \sqrt{3}}{\pi} V_{m} \approx 1.65 V_{m} \approx 2.34 V_{P R M S},
$$

Where $V_{m}$ is the peak rotor voltage magnitude.

\section{Simulation Results}

\subsection{Super-Synchronous Speed Range}

The stator current, rotor voltage, rotor current, stator active and reactive power, rotor active and reactive power, and electric torque are given in figures 2a-6a for the drive with rotor rectifier (system A), while these parameters are given in figures $2 b$ till $6 b$ for the drive with 3-phase rotor impedance (system B) at slip equal -0.08 (170rpm). Comparing results shows that the starting transients of the stator current of system $A$ are lower than system $B$, but its settling time is longer and its steady state value contains higher harmonics than system B. The rotor voltage starting transients and settling time for system $A$ are considerably higher than those for system $B$ and its steady state value contains higher harmonics, resulting in a nearly triangular voltage profile. Similar argument applies for the rotor current as demonstrated in the figures. Consequently, the starting transient, the settling time, and the steady state harmonics of stator active and reactive power in system $A$ are higher than its corresponding values in system $B$. In spite of the higher transient in the electric torque of system $B$, its steady state magnitude is smooth in system $B$ while it contains ripples in system $A$.

The stator current, rotor voltage, rotor current, stator active and reactive power, rotor active and reactive power, and electric torque are given in figures 7a-11a for the drive with rotor rectifier (system A), while these parameters are given in figures $7 b$ till $11 b$ for the drive with 3-phase rotor impedance (system B) at slip equal -0.21 (190rpm). Comparing results shows the higher starting transient of rotor current in system $A$ and higher harmonics of its steady state magnitude than for 
system $B$. It is worth noticing that the stator active and reactive power consumed from the grid is very high during starting for system $A$, but settles down to the same value of system $B$ at steady state. Also torque ripples for system $A$ are higher with slightly higher transient magnitude than the value in system $B$.

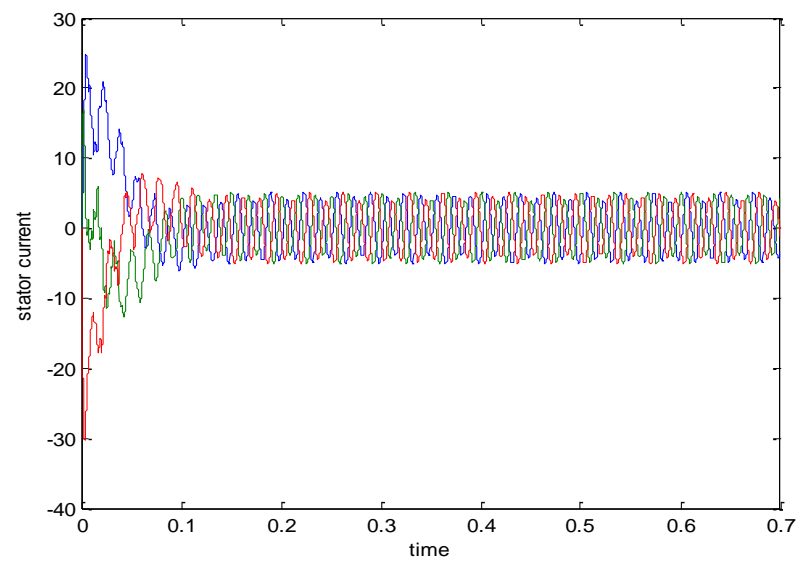

Fig.(2-a) Is of System A at 170rpm

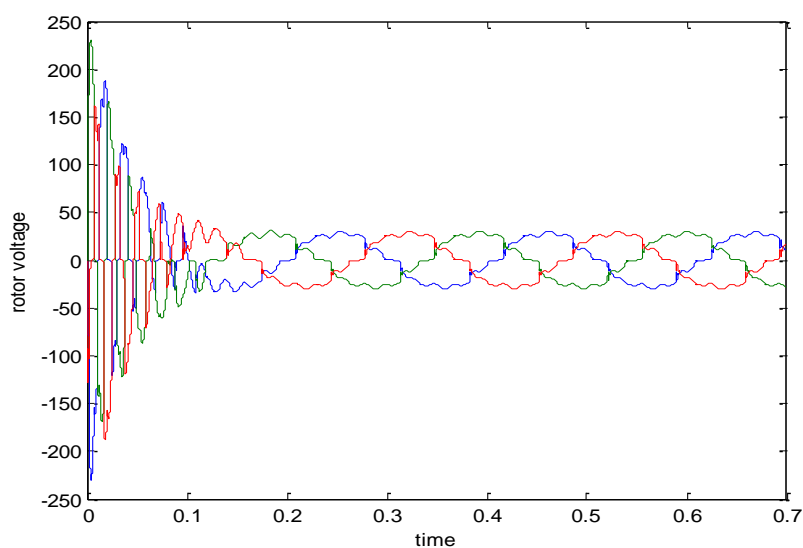

Fig.(3-a) Vr of System A at 170rpm

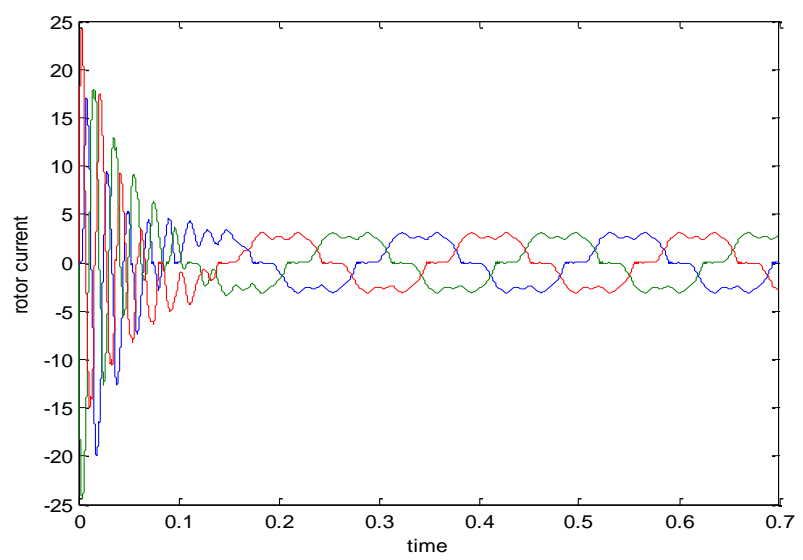

Fig.(4-a) Ir of System A at 170rpm

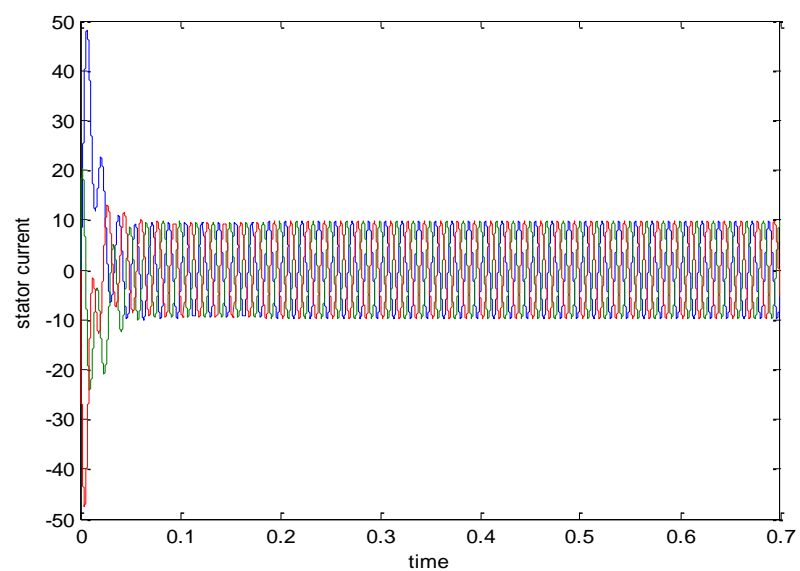

Fig.(2-b) Is of System B at 170rpm

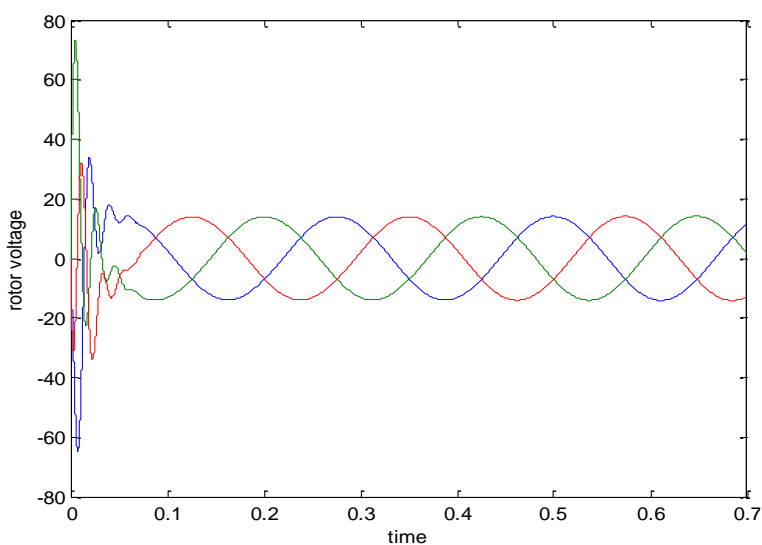

Fig.(3-b) Vr of System B at 170rpm

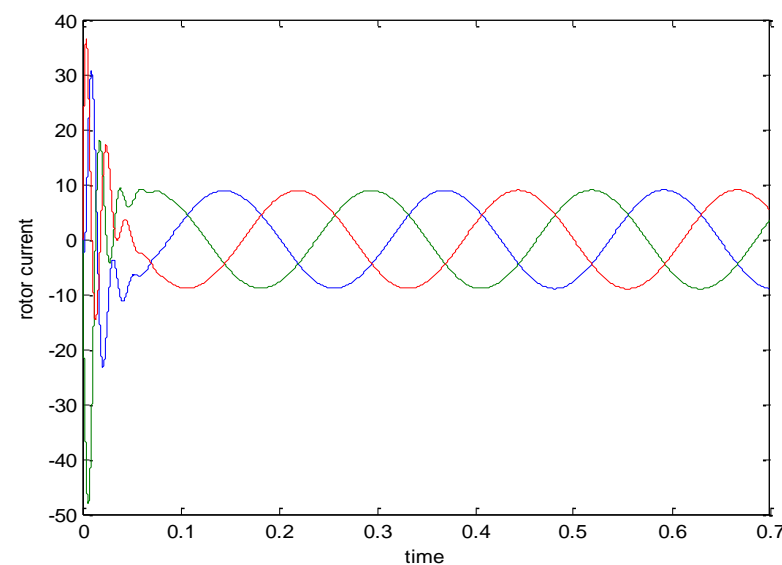

Fig.(4-b) Ir of System B at 170rpm 


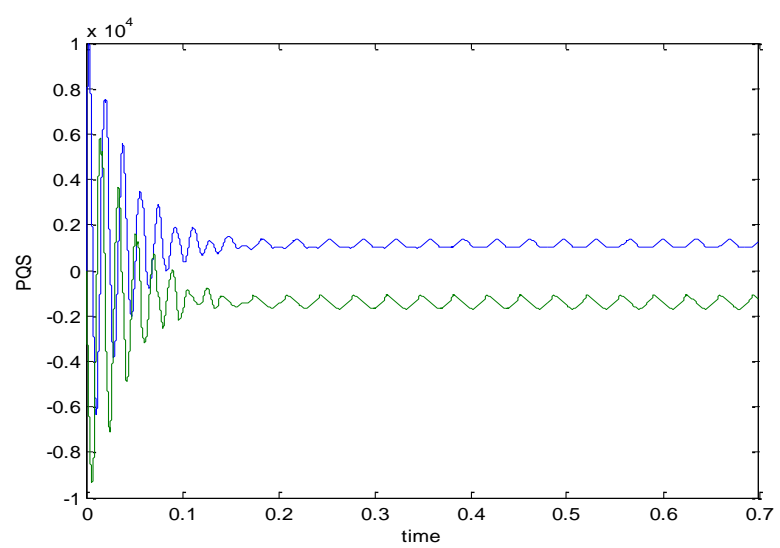

Fig.(5-a) Ps\&Qs of System A at 170rpm

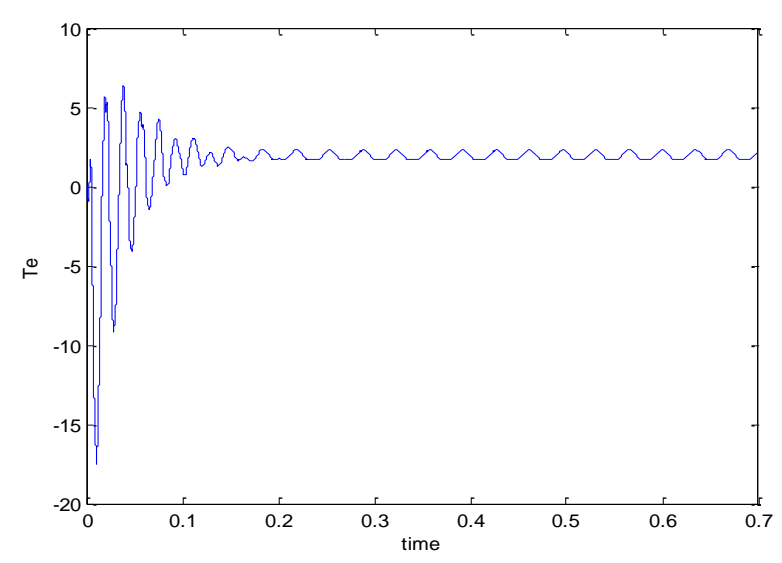

Fig.(6-a) Te of System A at 170rpm

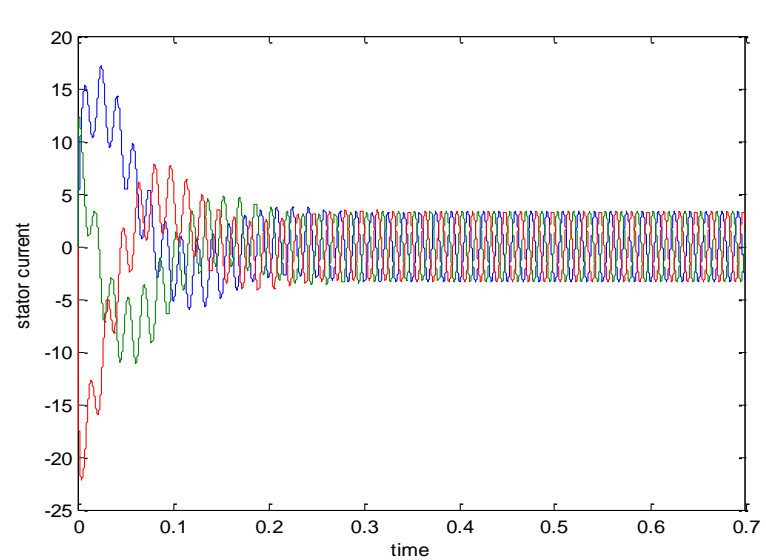

Fig.(7-a) Is of System A at 190rpm

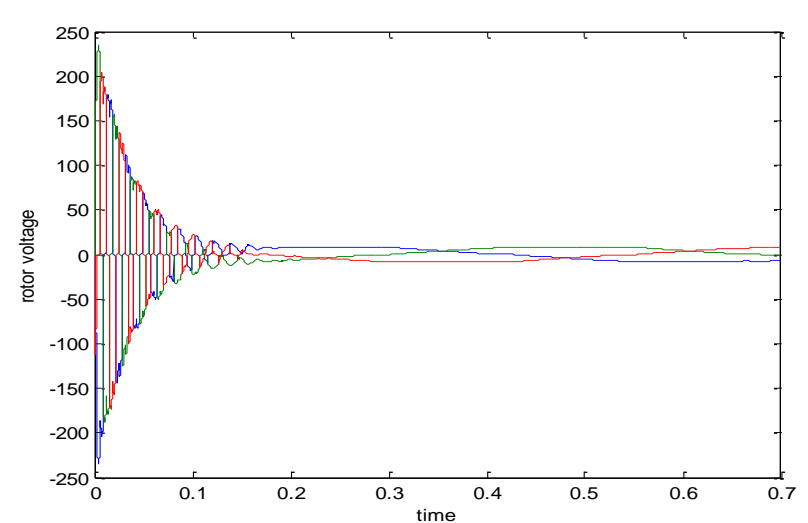

Fig.(8-a) Vr of System A

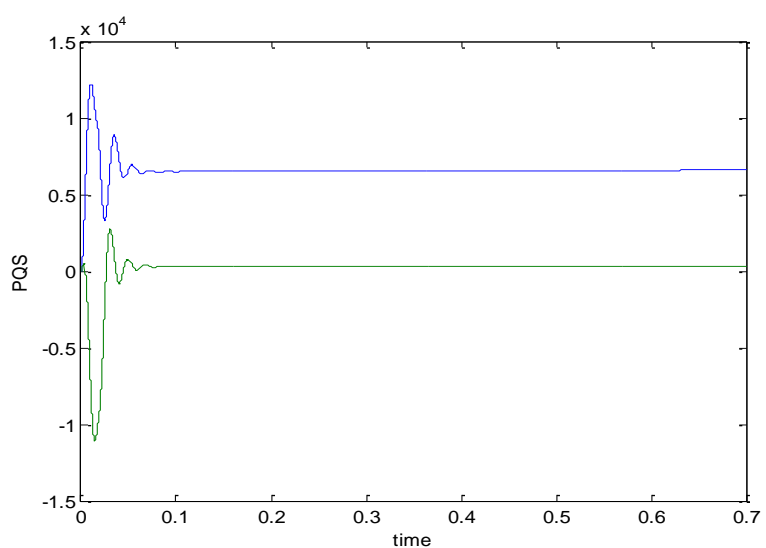

Fig.(5-b) Ps\&Qs of System B at 170rpm

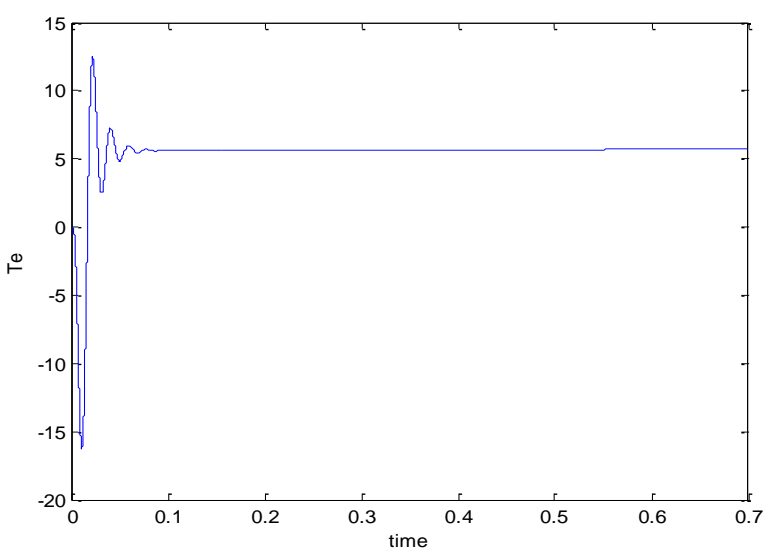

Fig.(6-b) Te of System B at 170rpm

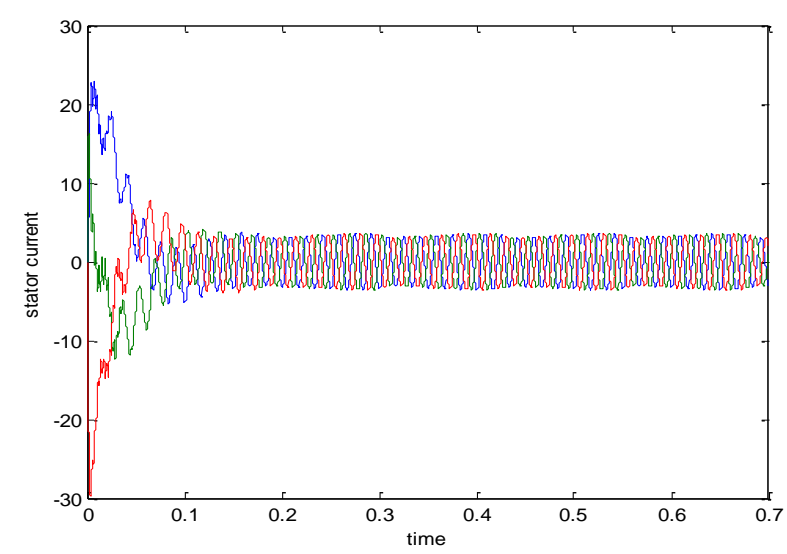

Fig.(7-b) Is of System B at 190rpm

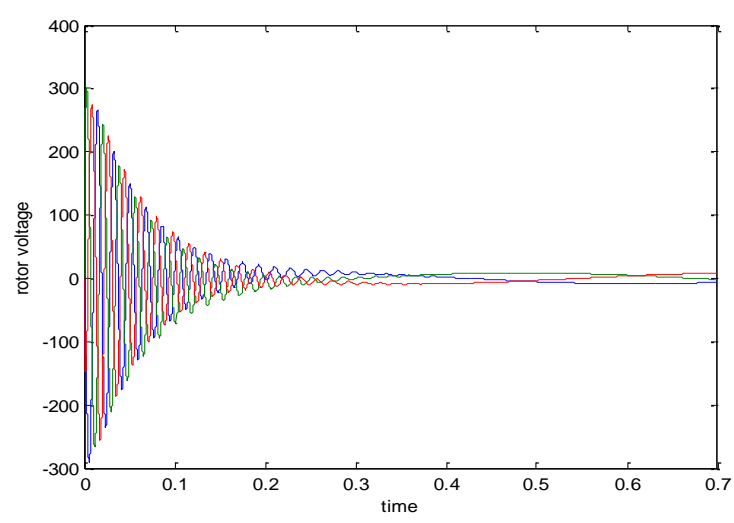

Fig.(8-b) Vr of System B 


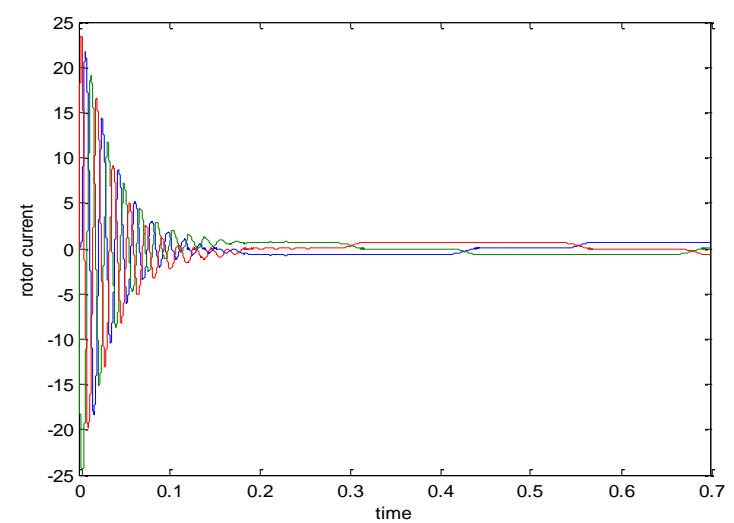

Fig.(9-a) Ir of System A

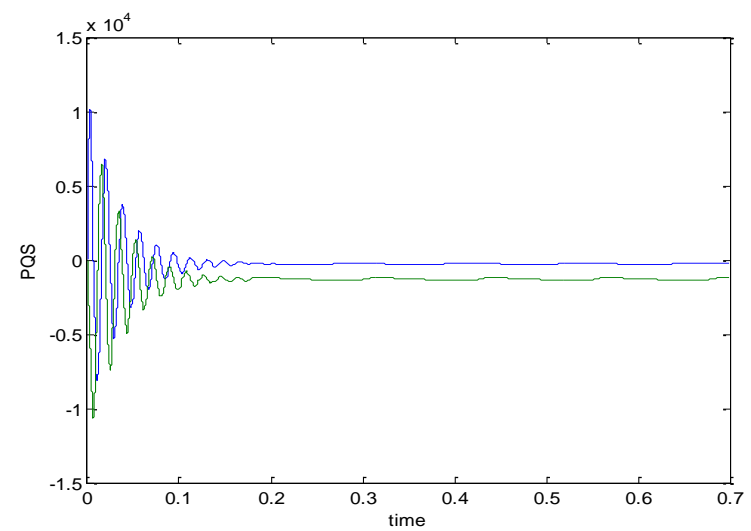

Fig.(10-a) Ps\&Qs of System A

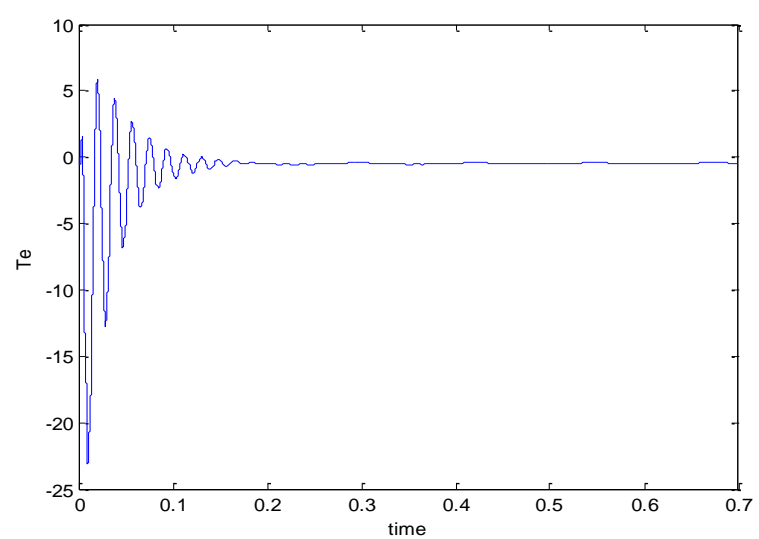

Fig.(11-a) Te of System A

\subsection{Sub-Synchronous Operation}

The stator voltage, stator current, rotor voltage, rotor current, stator active and reactive power, and electric torque are given in figures $12 \mathrm{a}-16 \mathrm{a}$ for the drive with rotor rectifier (system $A$ ), while these parameters are given in figures $12 \mathrm{~b}$ till $16 \mathrm{~b}$ for the drive with 3 -phase rotor impedance (system B) at slip equal 0.0445 (150rpm). The starting transient of the stator current of system $A$ is lower than system $B$, but its settling time is longer and its steady state value contains higher harmonics than system B.

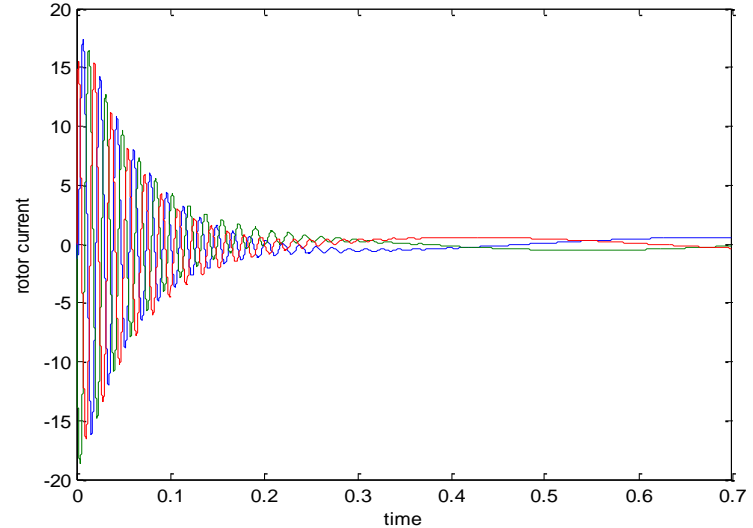

Fig.(9-b) Ir of System B at 190rpm

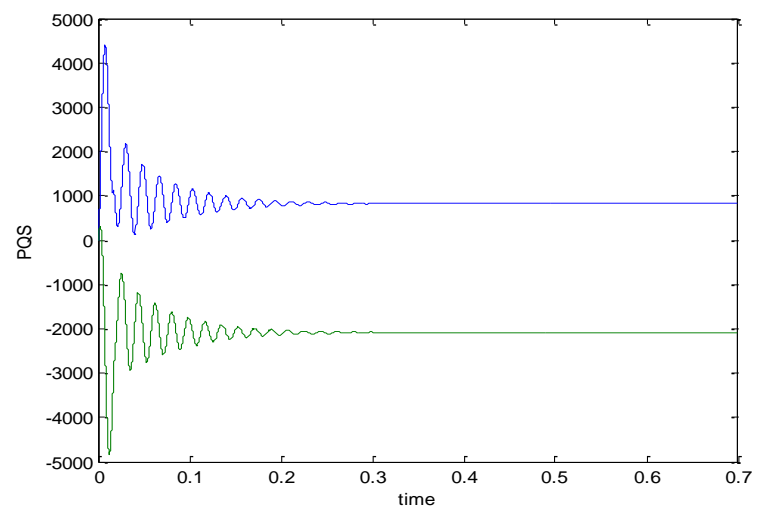

Fig.(10-a) Ps\&Qs of System A

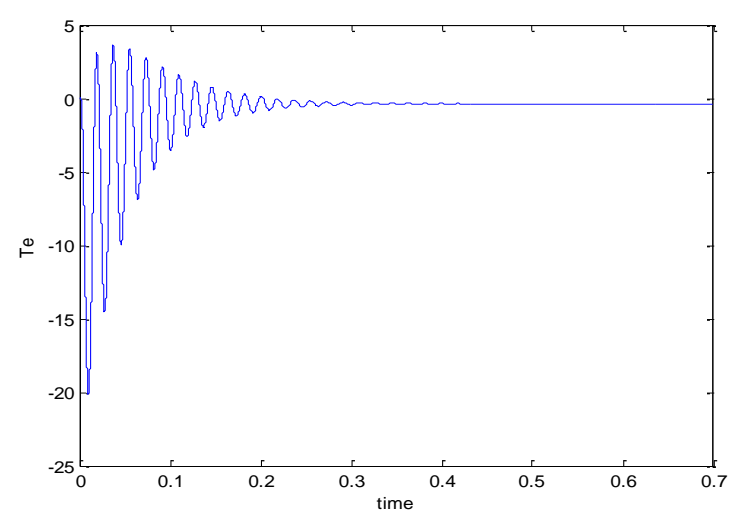

Fig.(11-b) Te of System B

The rotor voltage starting transients and settling time for system A are considerably higher than system B and its steady state value contains higher harmonics, resulting in a nearly triangular voltage profile. Similar argument applies for the rotor current as demonstrated in the figures. Consequently, the starting transient, the settling time, and the steady state harmonics of stator active and reactive power in system $A$ are higher than its corresponding values in system B. The steady state 
magnitude of the electromagnetic torque of system $A$ contains ripples, while it is smooth for system B.

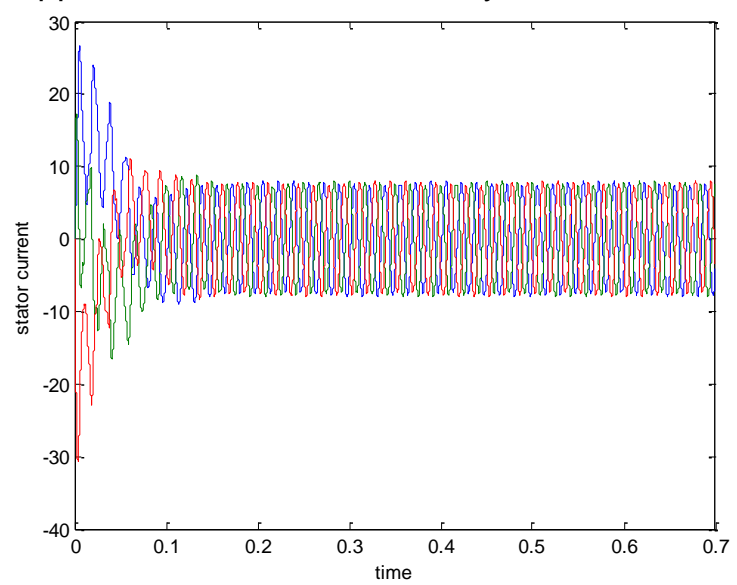

Fig.(12-a) Is of System A at 150rpm

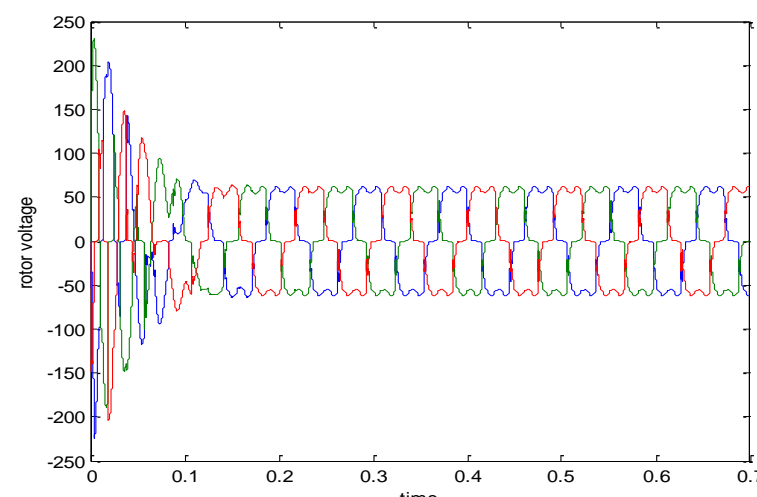

Fig.(13-a) Vr of System A at 150rpm

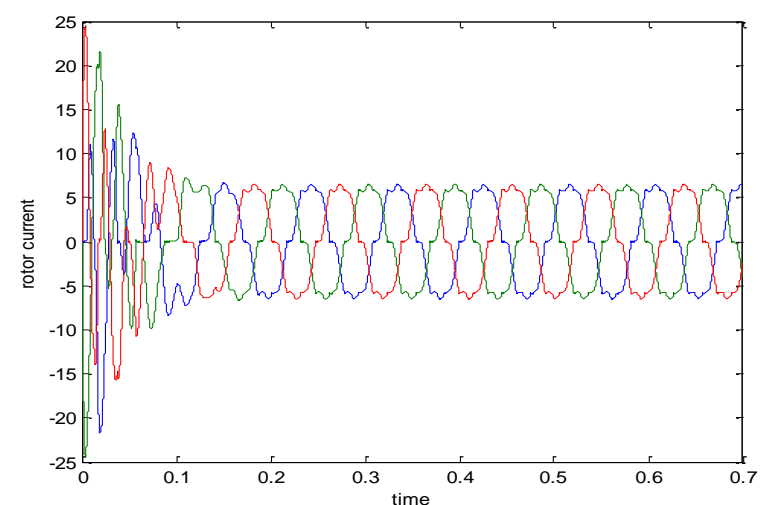

Fig.(14-a) Ir of System A at 150rpm

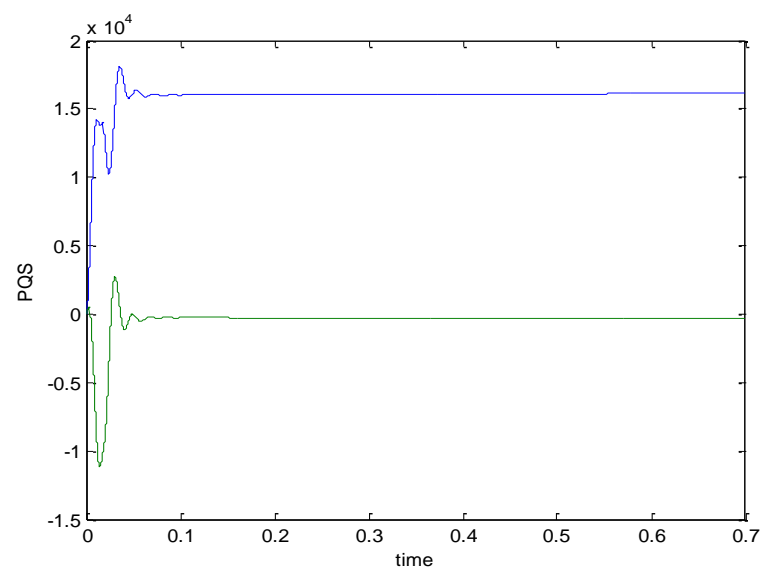

Fig.(15-a) Ps\&Qs of System A

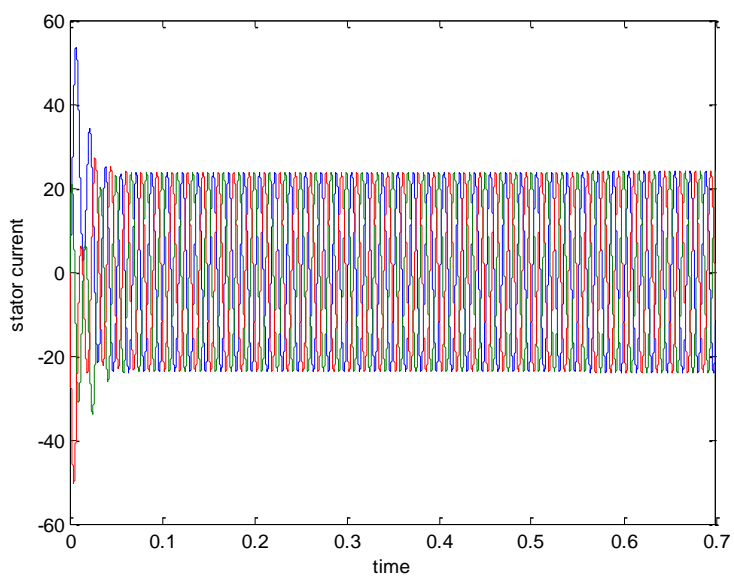

Fig.(12-b) Is of System B at 150rpm

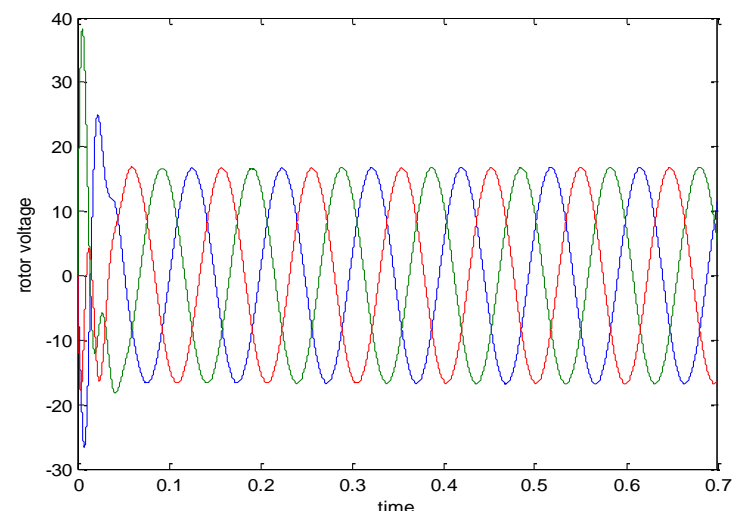

Fig.(13-b) Vr of System B at 150rpm

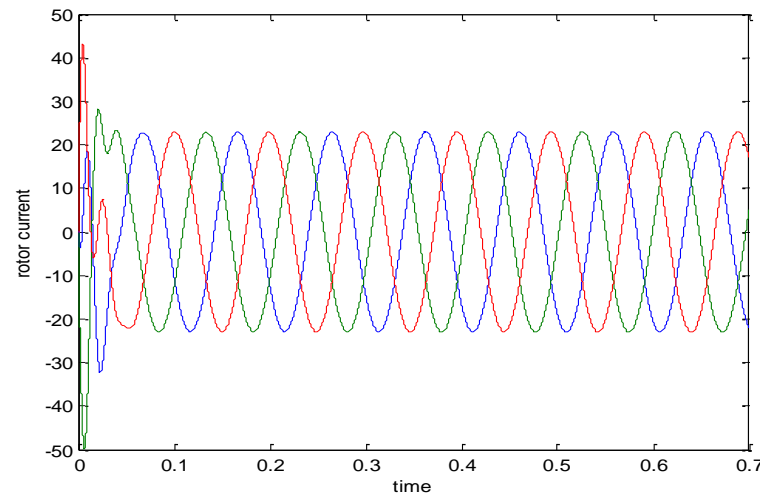

Fig.(14-b) Ir of System B at 150rpm

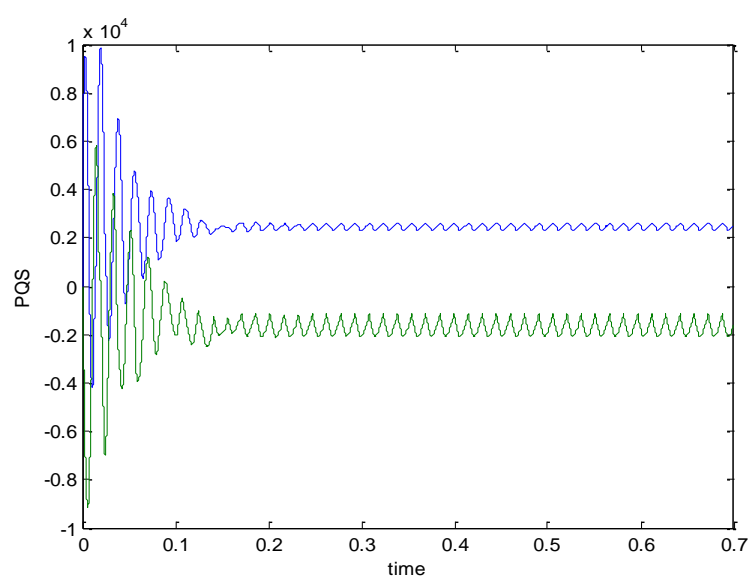

Fig.(15-b) Ps\&Qs of System 

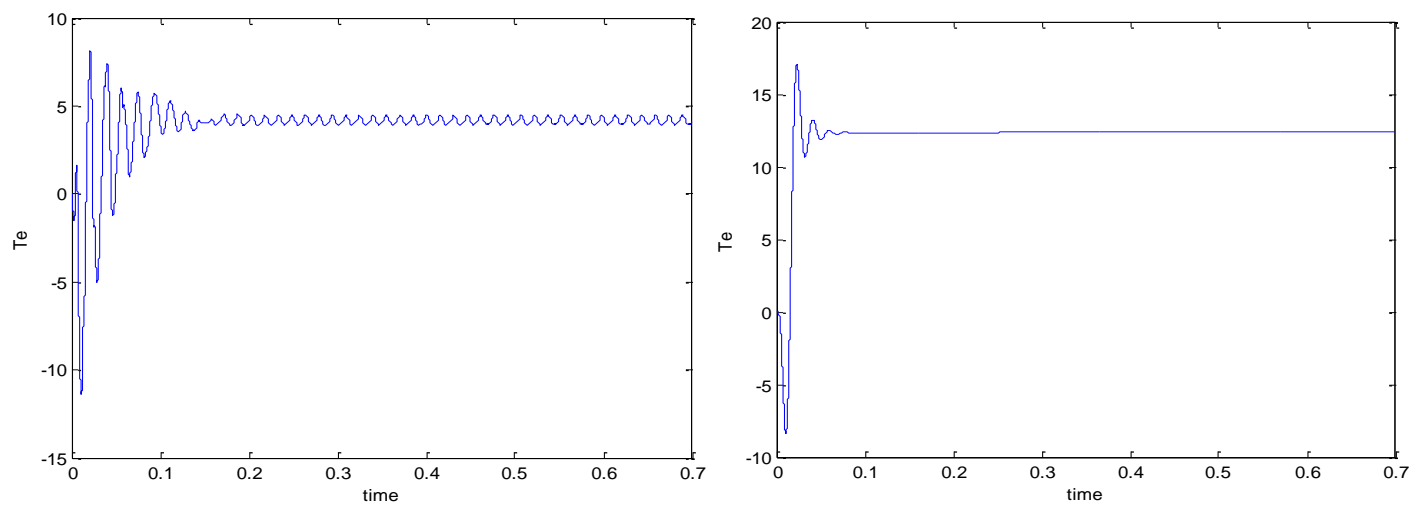

Fig.(16-a) Te of System A at 150rpm

Fig.(16-b) Te of System B at 150rpm

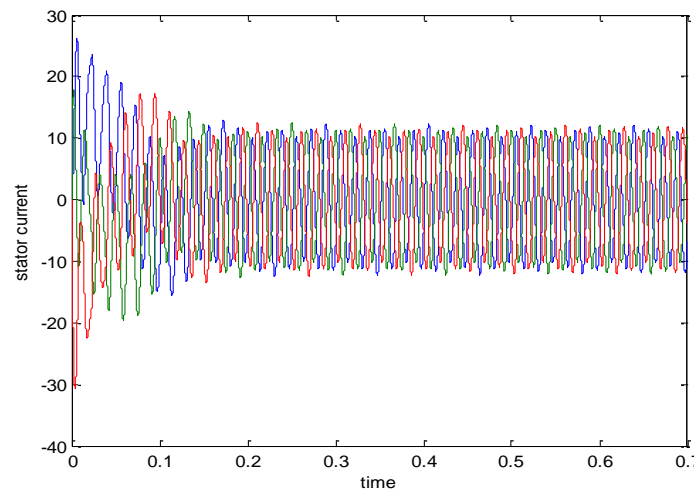

Fig.(17-a) Is of System A at $130 \mathrm{rpm}$

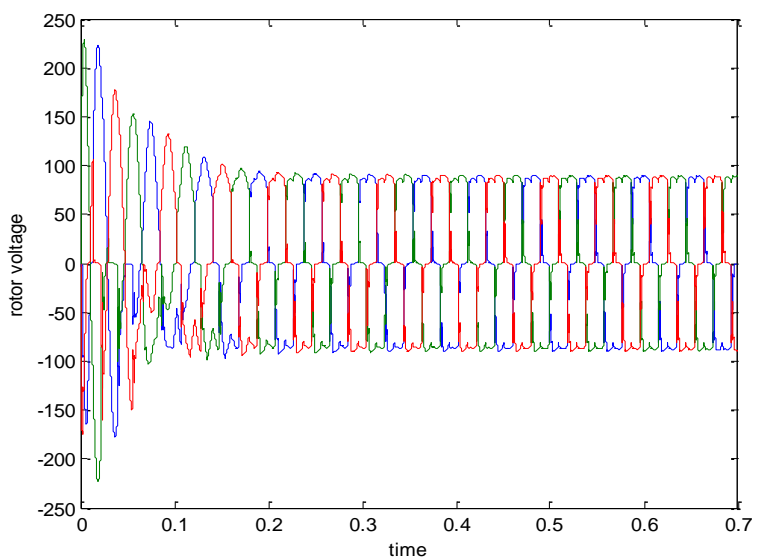

Fig.(18-a) Vr of System A

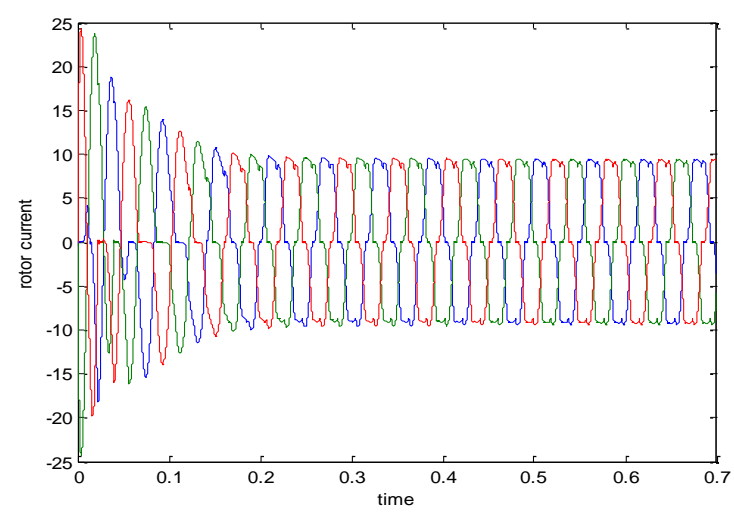

Fig.(19-a) Ir of System A

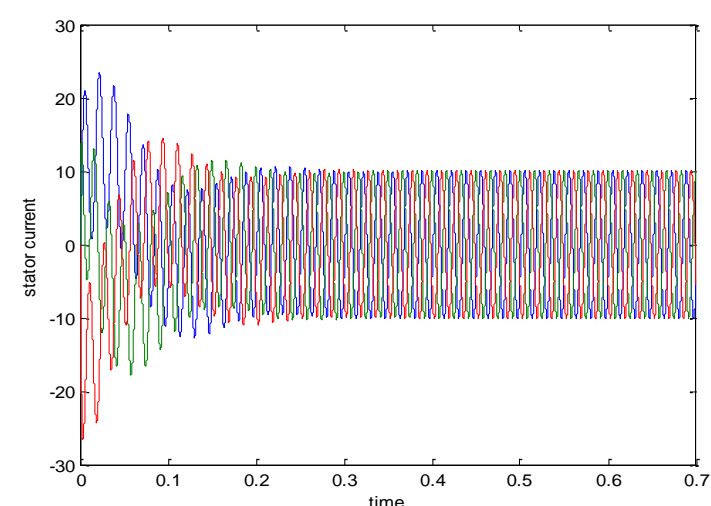

Fig.(17-b) Is of System B at $130 \mathrm{rpm}$

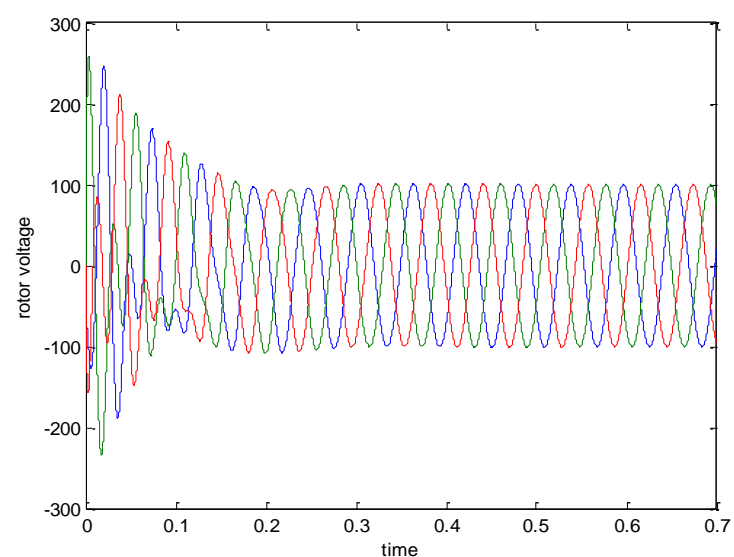

Fig.(18-b) Vr of System B

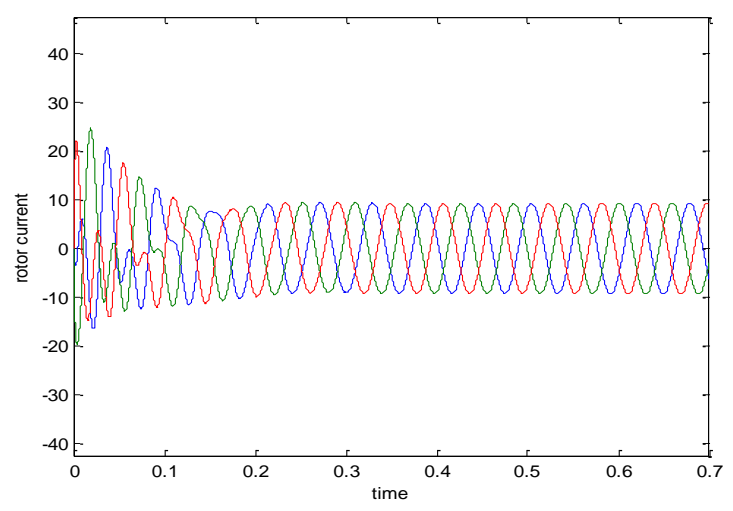

Fig.(19-b) Ir of System B 


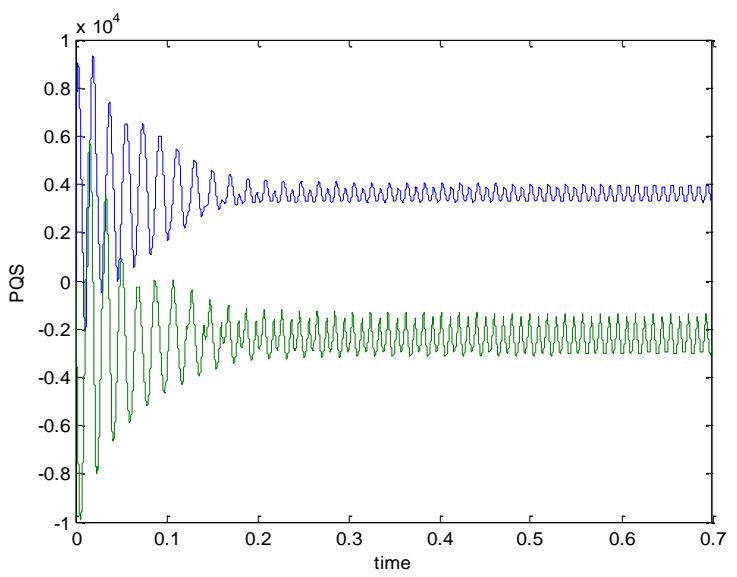

Fig.(20-a) Ps\&Qs of System A

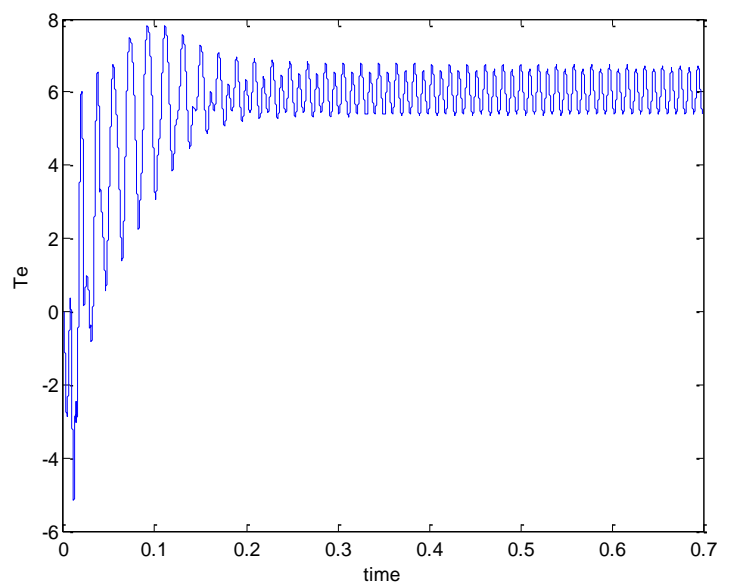

Fig.(21-a) Te of System A

The stator current, rotor voltage, rotor current, stator active and reactive power, rotor active and reactive power, and electric torque are given in figures 17a-21a for the drive with rotor rectifier (system A), while these parameters are given in figures $17 \mathrm{~b}$ till $21 \mathrm{~b}$ for the drive with 3-phase rotor impedance (system B) at slip equal 0.172 (130rpm). It is clear that the steady state stator current of system A contains more ripples and its transient peak and settling time are higher than those of system $B$. The transient magnitude and the settling time of the rotor voltage are also higher for system $A$ than in system $B$. The steady state rotor current of system B is pure sinusoidal, while it contains harmonics leading to a rectangular shape for system $A$. This is expected due to the rotor diode rectifier. Consequently, high transients and longer settling time in the stator active and reactive power occurred in system A are due to the high harmonics of the rotor current. Also torque ripples for system $A$ are higher with slightly higher transient magnitude than its value in system $B$.
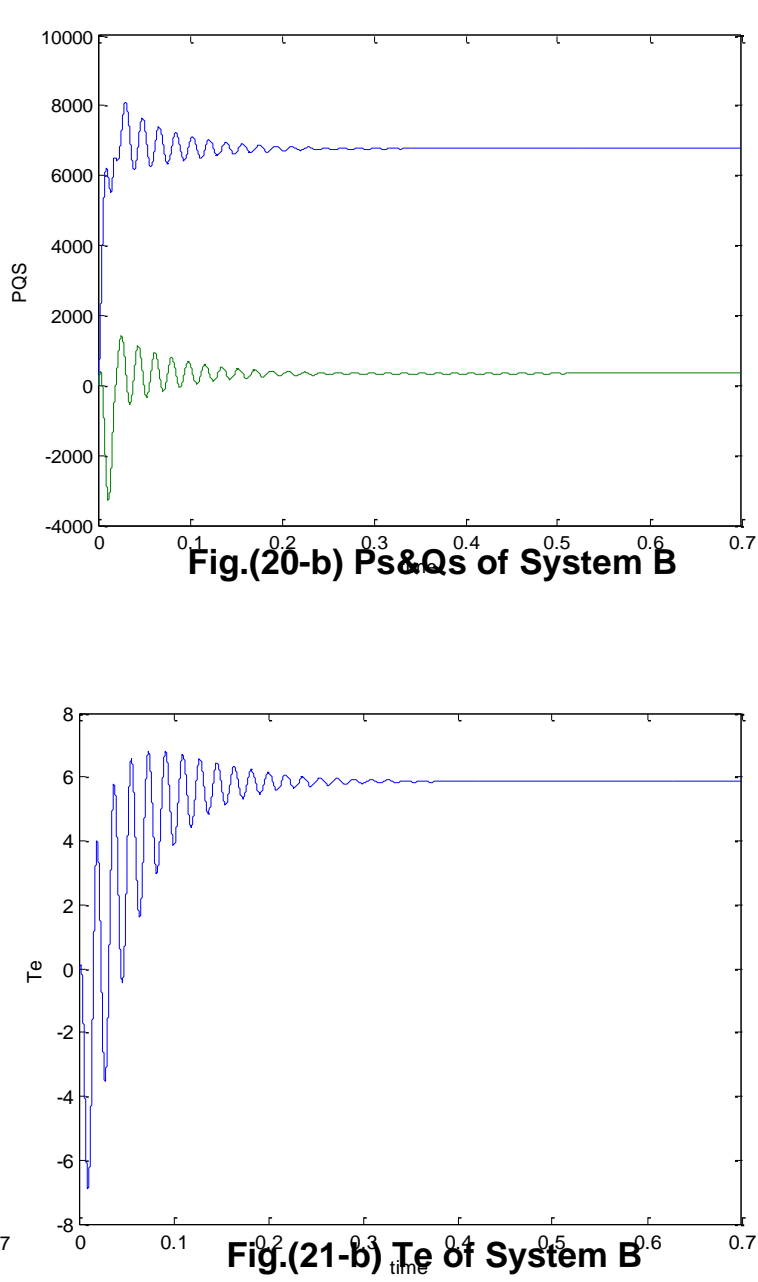

\section{Conclusion}

Results of comparing the performance of a wound rotor induction motor drive (WRIM) with two rotor impedance profiles are given. The first system involves a diode rectifier followed by variable impedance in the rotor circuit. The second system involves a three-phase variable impedance in the rotor circuit. The comparison concerns the magnitude of starting transients, the transients settling time for the stator voltage and current, the rotor voltage and current, the profile of the stator active and reactive power, the profile of the rotor active and reactive power, and the electric torque at sub-and super-synchronous speed. This comparison is helpful for deciding the more efficient drive to be utilized, and the wider speed range stable operation. Results proved the superiority of the system with three phase rotor impedance concerning the starting transient peaks, the settling time, and the lower harmonics of the steady state stator current, rotor voltage and rotor current. The range of stable operation is wider in the three phase rotor impedance system, which can be concluded from the higher distortion that occurs in the voltages and currents of the system involving the rectifier as the speed range is widened. 


\section{References}

[1] Nivedita Singh, Chandra Kumar Sahu, Anil Kumar Yadav, Roshan Sahu, Different Methods of Improvement in Speed, Power \& Efficiency of Induction Motor: Review Paper, Journal of Emerging Technologies and Innovative Research 7(5) (2020) 417-420.

[2] S. Ram, O.P. Rahi, V.Sarma, Comprehensive Literature Review on slip power recovery drives, Renewable and Sustainable Energy Reviews, 73 (2017) 922-934.

http://doi.org/10.1016/i.rser.2016.11.154

[3] Shiv Kurmar, Ajay Kumar, Himanshu Gupta, Review of Slip Power Recovery Scheme, International Journal of Recent Research Aspects, Special Issue: Engineering Research, (2015) 9398.

[4] [4] Oti Stephen Ejiofor, Okoli Chinweike, Idoko Hillary, Obe Titus, Ebele-Muolokwu, Dynamics of a Slip Power Recovery Scheme, Journal of Controller and converters, 4(3)(2019) 35-42. http://doi.org/10.5281/zenodo.3559326

[5] Ishan Bhardwaj, Bhupender Singhm, Simulation and Comparative Assessment of Slip Power Recovery Scheme, International Journal of Advanced Research in Electrical, Electronics and Instrumentation Engineering, 6 (7) (2017) 52945302.

\section{http://doi.org/10.15662/IJAREEIE.2017.0607010}

[6] J. Faiz, H. Barati, E. Akpinar, Harmonic Analysis and Performance Improvement of Slip Energy Recovery Induction Motor Drives, IEEE Trans. on Power Electronics, 16(3) (2001) 410-417.

http://doi.org/10.1109/63.923774

[7] B. K. Singh, K. B. Naik, Steady State Modeling and Performance Analysis of Static Slip Energy Recovery Controlled Slip Ring Induction Motor Drive, Proc. Of the international Multi Conference of Engineers and Computer Scientists, (IMECS), Hong Kong, (2009). http://www.iaeng.org/IMECS2016

[8] Ishan Bhardwaj, Bhupender Singh, Modelling and Simulation for Transformer Ratio Controlled Slip Power Recovery Scheme, International Research Journal of Engineering and Technology, 4(7) (2017) 2280-2285.

[9] Doug Phares, Tim Ruegg, Kelly Fishel, EnergySaving Project of 5500-HP 13-kv Wound Rotor Induction Motor on Kiln ID Fan Using a LowVoltage Slip Power Recovery Drive - A Case Study, IEEE Transaction on Industry Application, 53(6) (2017) 5997-6001.

http://doi.org/10.1109/CITCON.2017.79518
[10] D. Muralidharan, P. Anitha Rani, R. Aswani, Efficiency Improvement of WRIM Using DSP Controller by Adding Rotor Capacitance, International Journal of Engineering Research \& Technology,1(9), (2012) 1-10,

[11] K. Ranjith Kumar, S. Palaniswam, M.Manikandan, Performance Analysis of Wound Rotor Induction Motor by DSP Based Rotor Dynamic Capacitor Control, Journal of Theoretical and Applied Information Technology, 40 (1) (2012) 67-77.

[12] G. D. Marques, and Pedro Verdelho, A Simple SlipPower Recovery System with a DC Voltage Intermediate Circuit and Reduced Harmonics on the Mains, IEEE Transactions on Industrial Electronics, 47, (1) (2000) 123-132.

http://doi.org/10.1109/41.824134

[13] N. Kumar, T.R.Chelliah, S.P. Srivastava, Analysis of doubly-fed induction machine operating at motoring mode subjected to voltage sag, International Journal on Engineering Science and Technology, 19 (2016) 1117-1131.

\section{Funding}

No funding was received for conducting this study.

\section{Conflict of interest}

The authors have no conflicts of interest to declare that they are relevant to the content of this article.

\section{Author's contribution}

Both the authors equally contributed to this work.

About the License

(C) The author(s) 2021. The text of this article is open access and licensed under a Creative Commons Attribution 4.0 International License

\section{Cite this Article}

Mona N Eskander, Sanaa I Amer, Comparing the Performance of Induction Machine Drive with Different Rotor-Impedance Profiles, International Research Journal of Multidisciplinary Technovation, 3(2) (2021) 26-34. DOI: https://doi.org/10.34256/irimt2125 